\title{
Fuzzy Logic Control Based Standalone Wind Energy Conversion System For Dc Base Telecom Loads
}

\author{
G. Sankara babu ${ }^{1}$, Smt.V.Usha Reddy ${ }^{2}$ \\ PG Scholar, Department of EEE, SVU College of Engineering, Tirupati, Chittoor (dt), A.P, India ${ }^{1}$ \\ Assistant Professor, Department of EEE, SVU College of Engineering, Tirupati, Chittoor (dt), A.P, India ${ }^{2}$
}

\begin{abstract}
The main demand for renewable energy resources is increase in the price and limited availability of conventional energy resources. Available alternative sources of wind energy are neat and clean but due to the intermittent nature it can need back up. In order to ascertain continuous supply of potency felicitous storage technology is utilized as backup. In this paper, the sustainability of a $4-\mathrm{kW}$ hybrid of wind and battery system is investigated for meeting the requisites of a $3-\mathrm{kW}$ stand-alone dc load representing a base telecom station. A charge controller of battery bank charging and discharging depends on Fuzzy logic controller predicated maximum power point tracking and battery state of charge. The mechanical safety and electrical safety of wind energy conversion system is achieved by using pitch control technique. Both the control schemes are integrated and the efficacy is validated by testing it with various load and wind profiles in MATLAB/SIMULINK.
\end{abstract}

Keywords: Maximum Power Point Tracking (MPPT), Pitch Control, State Of Charge (SOC), Wind Energy Conversion System (WECS).

\section{INTRODUCTION}

The renewable source are being utilized to meet the ever considered for a 3-KW stand-alone dc load. The layout of increasing energy demand [1].Due to relatively low cost of the entire system is shown in fig.1.The specifications of electricity production [2] wind energy consider to be one of the WT, Self Exited induction Generator (SEIG), and potential source of clean energy for the future [3]. A battery bank are tabulated in the Appendix.The hybrid wind-battery system is considered to meet the load components of wind energy system is $4.2-\mathrm{kW}$, horizontal demand of a stand-alone Base Telecom Station (BTS).The axis wind turbine, gear box with a gear ratio of 1:8 and a advantage of battery energy storage for an isolated WECS $5.4 \mathrm{hp} \mathrm{SEIG} \mathrm{as} \mathrm{the} \mathrm{wind} \mathrm{Turbine} \mathrm{Generator(WTG).} \mathrm{Since}$ is discussed in [4].With battery energy storage it is the load is a stand-alone dc load the stator terminals of the possible to capture maximum power [5] from the available SEIG are connected to a capacitor bank for self-excitation. wind. A comparison of several maximum power point The ac output is rectified by three-phase uncontrolled tracking(MPPT) algorithms for small wind turbine (WT) is diode rectifier. However, there is a need for a battery carried out in [6] and [7]. In order to extract maximum backup to meet the load demand during the period of power form WECS the turbine needs to be operated at unavailability of optimal angular speed [7]. The BTS load requirement is modeled as a dc load which requires a nominal regulated voltage of $50 \mathrm{~V}$. The WECS is interfaced with the standalone dc load by means of rectification ac-dc and buck converter dc-dc to regulate the load voltage at the desired level. The proposed control scheme utilizes the turbine maximum power tracking technique with the battery State Of Charge(SOC) limit logic to charge the battery in a controlled manner. The MPPT logic [8] used here actually forces the turbine to operate at optimum Tip Speed Ratio(TSR) and hence is parameter independent. The battery charging current is always continuous with very low ripple thus avoiding harmonic heating. The change over between the modes for battery charging is affected based on the actual value of the SOC. Further it also provides protection against turbine over speed, over loading, and over voltage at the rectifier output by using pitch control [9].

\section{HYBRID WIND-BATTERY SYSTEM FOR AN ISOLATED DCLOAD}

The hybrid wind-battery system consists of 4-KW WECS and $400 \mathrm{Ah}, \mathrm{C} / 10$ lead acid battery bank. The system is

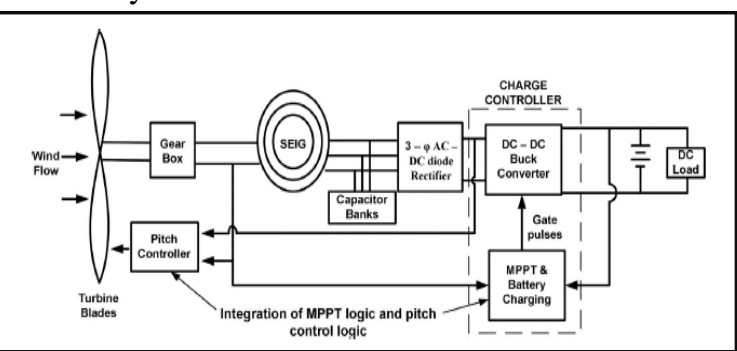

Fig. 1. Layout of hybrid wind-battery system for a standlone de load

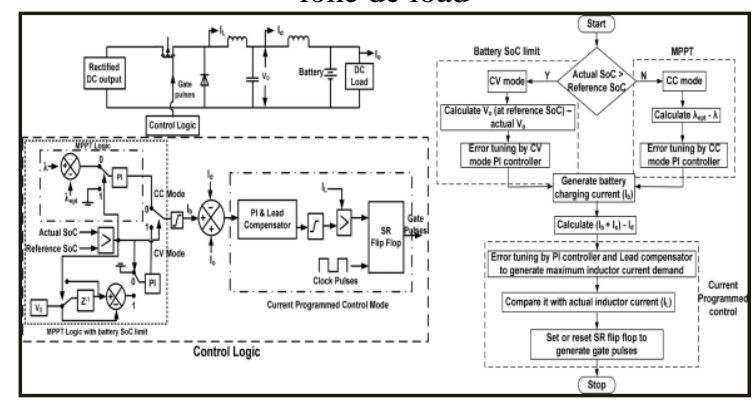

Fig. 2. Block schematic and flowchart of the charge controller circuit for battery 
sufficient wind power. This hybrid wind-battery system requires suitable control logic for interfacing with the load .The uncontrolled dc output of the rectifier is applied to the charge controller circuit of the battery. The charge controller is a dc-dc buck converter which determines the charging and discharging rate of the battery. The battery bank connected to the system can be act as source at the discharging mode of battery as well as while charging mode it can be act as load. However, apart from of this the battery ensures that the load terminal voltage is regulated.

The charging and discharging of the battery bank is realized by MPPT logic, the electrical and mechanical safety is controlled by using the pitch control technique and The integrated action of the battery charge and pitch controller ensures reliable operation of the stand-alone WECS. integrated action of the battery charge and pitch controller ensures reliable operation of the stand-alone WECS.

\section{CONTROL STRATEGY FOR STAND-} ALONE HYBRIDWIND-BATTERY SYSTEM

The wind flow is not available constantly. That's why we are using the control strategies in wind energy conversion system for getting the desired output in stand-alone control system. In this system AC-DC,DC-DC because of eliminated the voltage flickers and harmonics. The control scheme for a

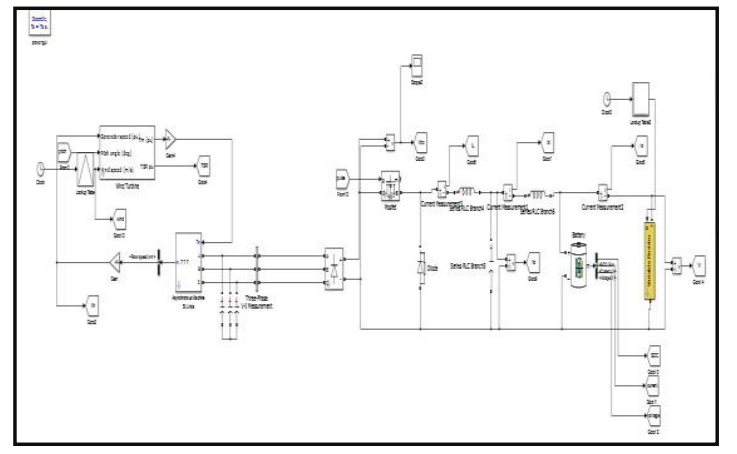

Fig.3: hybrid wind energy conversion system for dc base telecom station

stand-alone hybrid wind battery system includes the charge controller circuit for battery banks and pitch control logic to ensure WT operation within the rated value.

\section{A. Charge Controller for the Battery Bank:}

In MATLAB simulation we are using the $400 \mathrm{Ah}, \mathrm{C} / 10$ battery bank using a dc-dc buck converter. However, the current required for charging the battery bank depends on the battery State Of Charge. A typical battery generally charges at a constant current (CC), i.e., $\mathrm{C} / 10$ rate mode till battery SOC reaches a certain level (90\%-98\%). This is referred to as $\mathrm{CC}$ mode of battery charging. The $\mathrm{CC}$ mode charges the battery as fast as possible.

Beyond this SOC, the battery is charged at a constant voltage (CV) which is denoted as CV mode of battery charging in order to maintain the battery terminal voltage.

\section{B. Control Strategy:}

The implementation of the charge control logic as shown in Fig. 2 is carried out by three nested control loops. The outer most control loop operates the turbine following MPPT logic with battery SOC limit it is clearly shown in fig3 and fig5. To implement the MPPT logic, the actual tip speed ratio (TSR) of turbine is compared with the optimum value The error is tuned by a PI controller to generate the battery current demand as long as the battery $\mathrm{SOC}$ is below the $\mathrm{CC}$ mode limit. Beyond this point, the SOC control logic tries to maintain constant battery charging voltage. This in turn reduces the battery current demand and thus prevents the battery bank from overcharging. The buck converter inductor current command is generated in battery current $\left(I_{b}\right)$ with respect to the inductor current $\left(I_{L}\right)$. The immediate control loop. To design the controller, it is essential to model the response of the transfer function from fig.4.

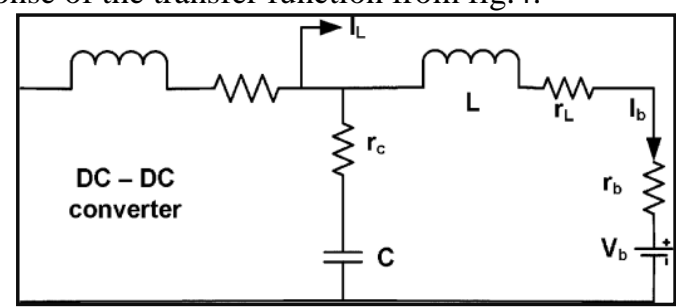

Fig. 4.Circuit representation of buck converter output.

The transfer function can be computed from Fig. 4 and is given by

$$
\frac{\mathrm{I}_{\mathrm{b}}(\mathrm{s})}{\mathrm{I}_{L}(\mathrm{~S})}=\frac{r_{c} C s+1}{L C S^{2}+\left(r_{L}+r_{c}+r_{b}\right) C S+1}
$$

As shown in Fig. 4, the battery is assumed to be a CV source with a small internal resistance $\left(r_{b}\right)$. The Effective Series Resistances(ESR) of the capacitor $\left(r_{c}\right)$ and the inductor $\left(r_{L}\right)$ are also considered. The ESR of the capacitor and the inductor are taken to be $1 \mathrm{~m} \Omega$ each. The battery internal resistance is $10 \mathrm{~m} \Omega$.

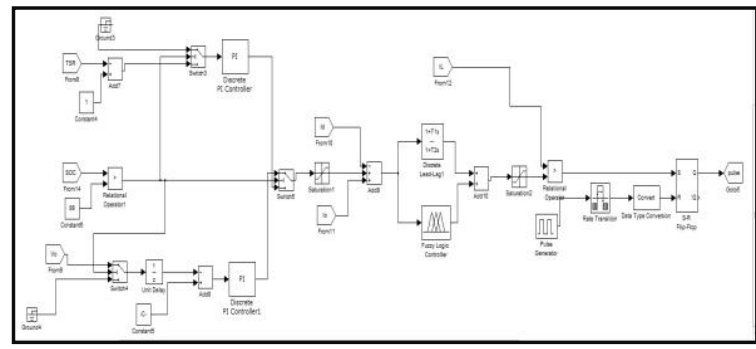

Fig5:MPPT Logic Controller

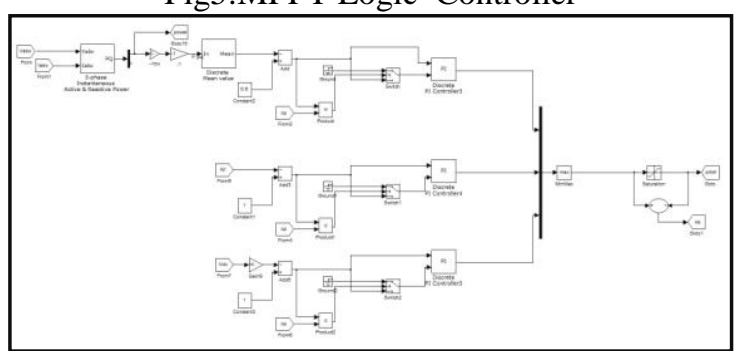

Fig. 6.:Pitch control scheme for a stand-alone WECS.

For regulating the peak-to-peak $(p-p)$ ripple of battery current and converter output voltage within $2 \%$ of the 
rated value the $\mathrm{L}$ and $\mathrm{C}$ are calculated to be $10 \mathrm{mH}$ and 5 $\mathrm{mF}$, respectively For controlling the battery current the actual converter output current $\left(I_{d}\right)$ is compared with the reference $\left(I_{b}+I_{a}\right)$ and the error is processed by a cascade of PI and lead compensator. The PI controller is designed as an inverted zero. To maintain the phase margin of the open-loop system the frequency of this zero is 50 times lower than the crossover frequency. To improve the phase margin of the battery charging current control loop a lead compensator is connected in flow with the PI controller as shown in Fig. 2 The zero and pole of the lead compensator are designed to have a positive phase margin and to limit the crossover frequency to about $14 \%$ of the switching frequency.

In order to check the over loading of turbine (and its consequent stalling) the lead compensator output is first passed through an adjustable current limiter. The lower limit is fixed to zero and the upper limit is changed according to the maximum power available at a given wind speed. it is shown in fig.5. The output of this limiter is used as the reference for the current controller in the dcdc converter. Finally, in the inner most loop the actual inductor current is made to track the reference using peak current mode control. The compensated output of the intermediate loop is compared with the instantaneous inductor current of the buck converter. The output of the comparator is applied to an SR flip flop to generate the gate pulses for the $\mathrm{dc}-\mathrm{dc}$ buck converter. The frequency of the clock pulses is $2 \mathrm{kHz}$. The frequency of the gate pulse is equal to the clock pulse frequency. The generating the clock pulses in this method is known as the current programmed control technique. Inductor current exceed the rated current at that time it can be passed through the buck converter for reducing the current. This happens because with increase in blade pitch the lift coefficient reduces which results in decreasing the value of $C_{\boldsymbol{P}}$. So, the pitch control mechanism controls the power output by reducing the power coefficient at higher wind speeds. Below the rated wind speed the blade pitch is maintained at zero degree to obtain maximum power. The pitch controller increases the blade pitch as the WT parameters exceed the rated value.

\section{MODES OF BATTERY CHARGING} In $\mathrm{CC}$ mode of Battery charging and $\mathrm{CV}$ mode of Battery charging already discussed in III.

\section{Pitch Control Scheme:}

The pitch control scheme is shown in Fig. 6 As seen the P.U value of each input is compared with 1 to calculate the error The errors are adjusted by PI controller. The "MAX" block chooses the maximum output from each PI controller which is then passed on to a limiter to generate the pitch command for the WT. The actual pitch command is compared with the limited value. The lower limit of the pitch command is set at zero.

There arises an error when the actual pitch command goes above or below the specified limit. This is multiplied with the error obtained from each of the comparator. The product is compared with zero to determine the switching logic for integrator. This technique is carried out to avoid integrator saturation. The pitch controller changes the pitch command owing to variation in turbine rotation speed, power, and output voltage of rectifier, which ensures safe operation of the WECS.

\section{FUZZY CONTROLLER}

Fuzzy logic uses fuzzy set theory, in which a variable is member of one or more sets, with a specified degree of membership. Fuzzy logic allow us to emulate the human reasoning process in computers, quantify imprecise information, make decision based on vague and in complete data, yet by applying a "defuzzification" process, arrive at definite conclusions.

The FLC mainly consists of three blocks

- Fuzzification

- Inference

- Defuzzification

\section{RULES:}

The rules can be implemented by using mamdani method by using the and rule

\begin{tabular}{|l|l|l|l|l|l|}
\hline CE & NB & NS & ZE & PS & PB \\
\hline NS & ZE & ZE & PB & PB & PB \\
\hline ZE & PS & ZE & ZE & ZE & NS \\
\hline PS & NS & NS & NS & ZE & ZE \\
\hline PB & NS & NB & NB & ZE & ZE \\
& & & & & \\
\hline
\end{tabular}

$\mathbf{E}=$ Error

$\mathbf{C E}=$ Change in Error

NB $=$ Negative Big

NS $=$ Negative small

$\mathbf{Z E}=$ Zero Error

$\mathbf{P S}=$ Positive Small

PB = Positive Big

\section{RESULTS AND DISCUSSIONS}

The system is connected to a load profile varying in steps from 0 to $4 \mathrm{kw}$. The WT factors like shaft speed, TSR, blade pitch and output power are analyzed with variation in wind speed conditions. The current profile of the converter, load, and the battery are also supervised with the wind profile.

To ensure continuous power flow, load demand is given more priority over battery charging. The WT and battery parameters are observed for the following wind profiles.

1. Gradual rise and fall in wind speed.-fig-7

2. Step variation in wind speed.-fig- 8

3. Arbitrary variation in wind speed.-fig-9 
A gradual rise and fall in wind speed as shown in Figures $7,8 \& 9$. The results also demonstrate the change in battery SOC for all possible wind profiles. From Figs 7-9, it is observed, that when the wind speed is below the rated value $(10 \mathrm{~m} / \mathrm{s})$ the MPPT scheme regulates the TSR of WT at its optimum value Irrespective of the variation in wind profile. Thus maximum power is extracted from WECS at all wind speeds to meet the load requirement and charge the battery bank.

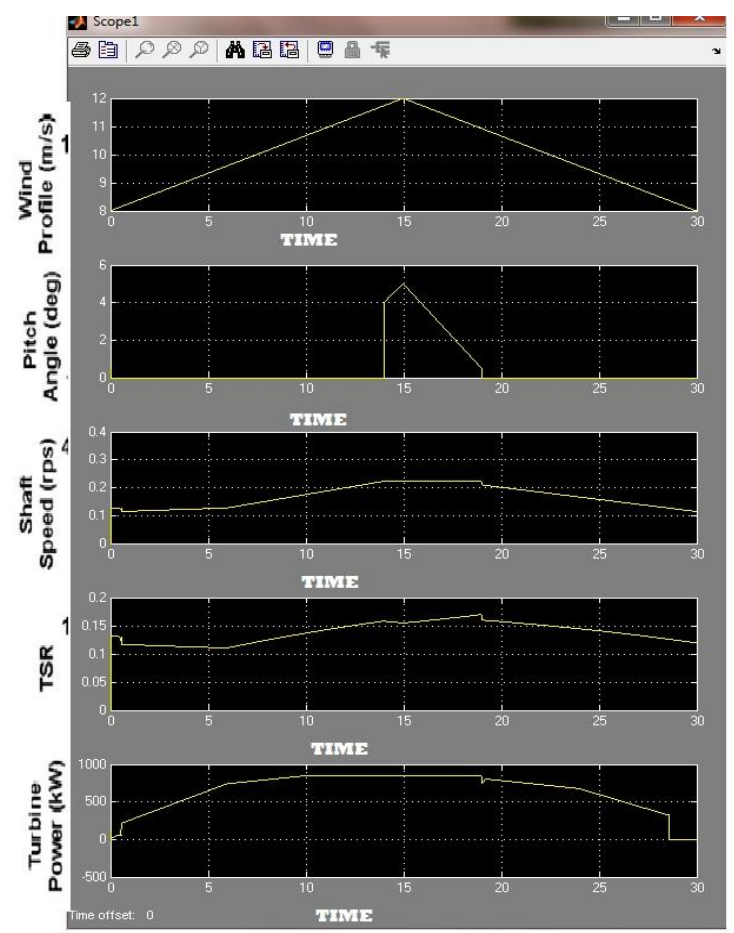

(a)

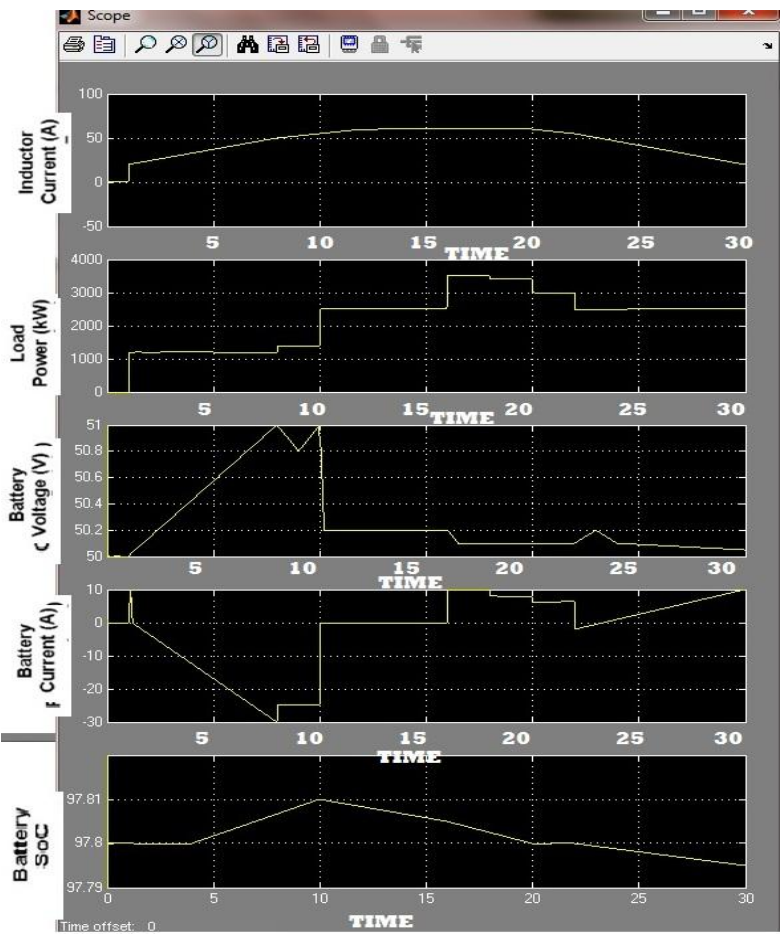

(b)

Fig.7.(a)WT and (b) battery parameters under the influence of gradual variation of wind speed.

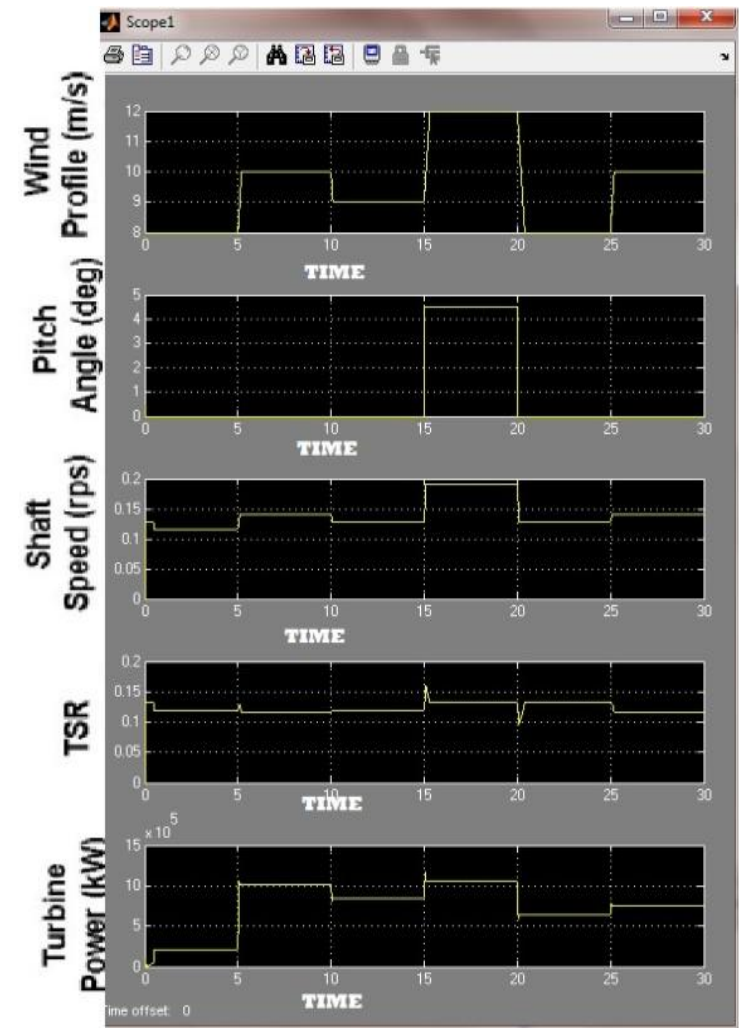

(a)

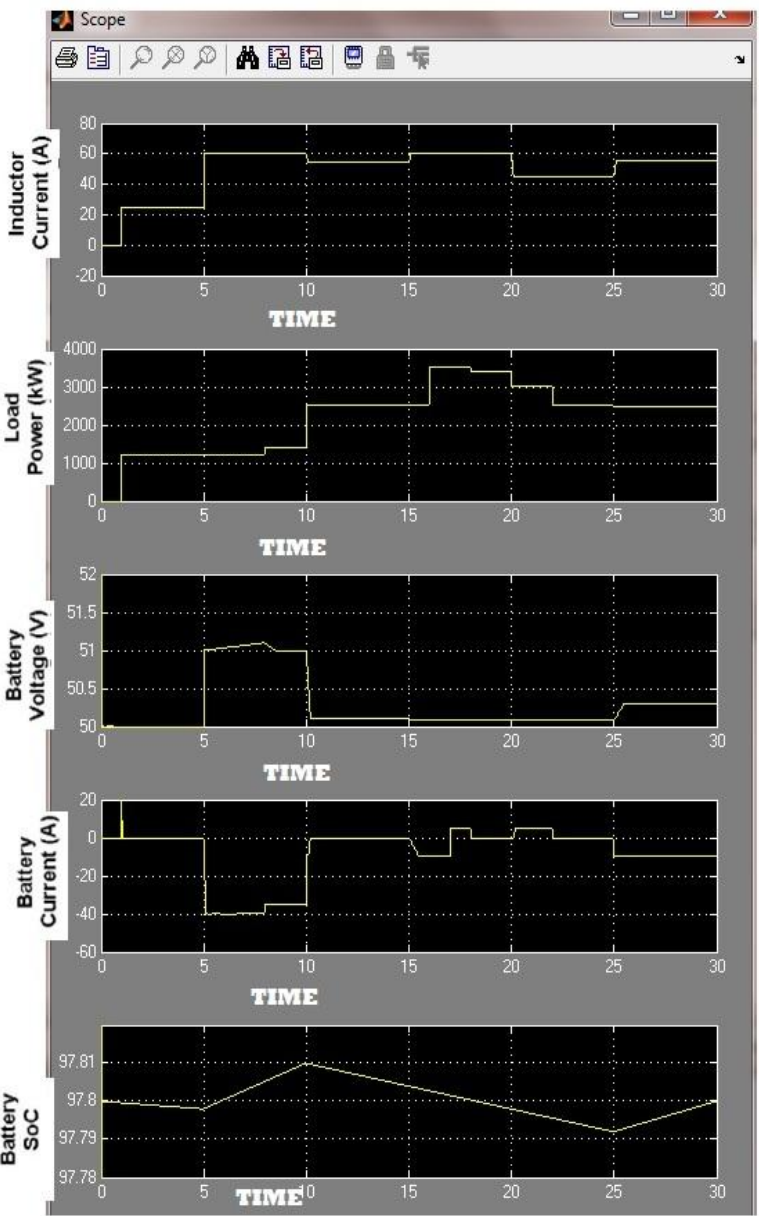

(b)

Fig. 8.(a)WT and (b) battery parameters under the influence of step variation of wind speed. 
DScope1

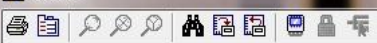

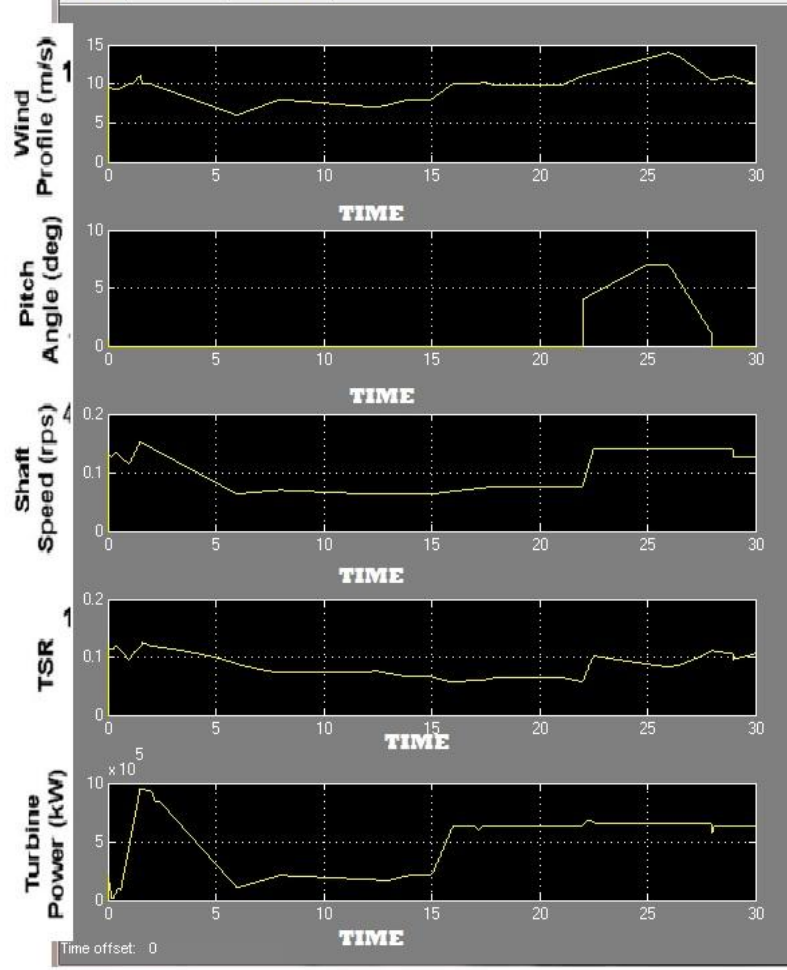

(a)

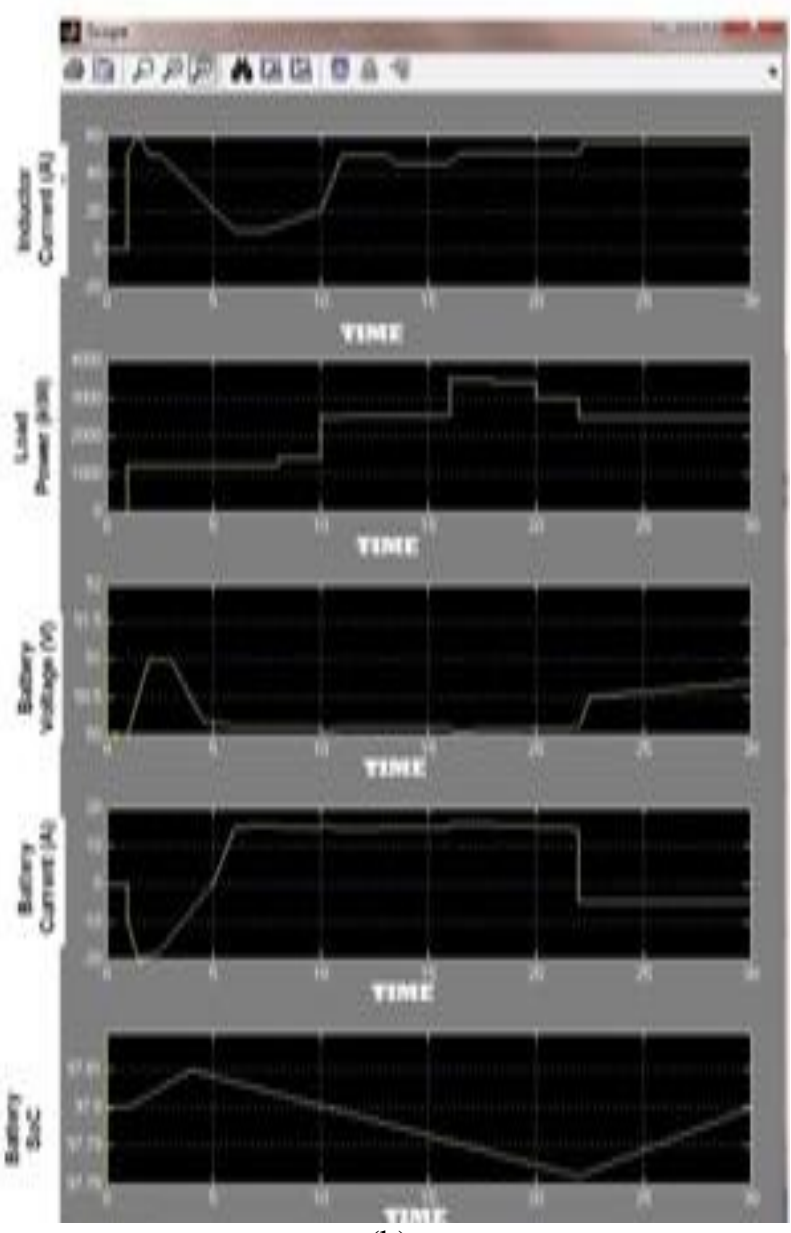

(b)

Fig. 9. (a) WT and (b) battery parameters under the influence of step variation of wind speed.

\section{CONCLUSION}

In this paper, a hybrid wind-battery system is selected to supply the desired load power. To moderate the random characteristics of wind flow the WECS is interfaced with the load by suitable controllers. The control logic put into practice in the hybrid set up includes the charge control of battery bank using MPPT and pitch control of the WT for assuring electrical and mechanical safety. The pitch control logic guarantee that the rectifier voltage does not lead to an overvoltage situation. The hybrid wind-battery system along with its control logic is employed in MATLAB/ SIMULINK and is tested with various wind profiles.

\section{Appendix:}

Table1 WT System Specifications

\begin{tabular}{|l|l|}
\hline \multicolumn{1}{|c|}{ PARAMETERS } & \multicolumn{1}{c|}{$\begin{array}{c}\text { VALUE } \\
\text { (UNITS) }\end{array}$} \\
\hline Rated Power & $4000 \mathrm{~W}$ \\
\hline Radius & $2.3 \mathrm{~m}$ \\
\hline Cut In Wind Speed & $4 \mathrm{~m} / \mathrm{s}$ \\
\hline Rated Wind Speed & $10 \mathrm{~m} / \mathrm{s}$ \\
\hline Inertia Co-Efficient & $7 \mathrm{kgm}$ \\
\hline Optimu Tip Speed Ratio & 7 \\
\hline $\begin{array}{l}\text { Optimum Power } \\
\text { Coeficient }\end{array}$ & 0.41 \\
\hline
\end{tabular}

TABLE II Squirrel Cage Induction Machine Specifications

\begin{tabular}{|l|l|}
\hline \multicolumn{1}{|c|}{ PARAMETERS } & \multicolumn{1}{c|}{$\begin{array}{c}\text { VALUE } \\
\text { (UNITS) }\end{array}$} \\
\hline Rated Power & $5.4 \mathrm{HP}$ \\
\hline Stator Resistance & $2.6 \Omega$ \\
\hline Statorleakage Inductance & $4 \mathrm{mH}$ \\
\hline Mutual Inductance & $240 \mathrm{mH}$ \\
\hline Rotor Resistance & $2 \Omega$ \\
\hline $\begin{array}{l}\text { Rotor Leakage } \\
\text { Impedence }\end{array}$ & $4 \mathrm{mH}$ \\
\hline Excitation Capacitance & $15 \mu \mathrm{F}$ \\
\hline
\end{tabular}

TABLE-III Battery Specifications

\begin{tabular}{|c|c|}
\hline PARAMETERS & VALUE (UNITS) \\
\hline Ampere Hour Rating & $400 \mathrm{AH}$ \\
\hline Nominal Voltage & $48 \mathrm{~V}$ \\
\hline Fully Charged Voltage & $55.2 \mathrm{~V}$ \\
\hline Charging Rate & $\mathrm{C} / 10$ \\
\hline
\end{tabular}

\section{REFERENCES}

[1]. A. D. Sahin, "Progress and recent trends in wind energy," Progress in Energy Combustion Sci., vol. 30, no. 5, pp. 501-543, 2004.

[2]. R. D. Richardson and G. M. Mcnerney, "Wind energy systems," Proc. IEEE, vol. 81, no. 3, pp. 378-389, Mar. 1993.

[3]. R. Saidur, M. R. Islam, N. A. Rahim, and K. H. Solangi, "A review on global wind energy policy," Renewable Sustainable Energy Rev., vol. 14,no. 7, pp. 1744-1762, Sep. 2010.

[4]. N. S. Hasan, M. Y. Hassan, M. S. Majid, and H. A. Rahman, "Review ofstorage schemes forwind energy systems," Renewable Sustainable EnergyRev., vol. 21, pp. 237-247, May 2013.

[5]. A. M. D. Broe, S. Drouilhet, and V. Gevorgian, "A peak power tracker forsmall wind turbines in battery charging applications," IEEE Trans. Energy convers., v vol. 14, no. 4, pp. 1630-1635, Dec. 1999. 
[6]. R. Kot, M. Rolak, and M. Malinowski, "Comparison of maximum peakpower tracking algorithms for a small wind turbine," Math.Comput.Simul., vol. 91, pp. 29-40, 2013.

[7]. M. Narayana, G. A. Putrus, M. Jovanovic, P. S. Leung, and S. McDonald,"Generic maximum power point tracking controller for small-scale windturbines," Renewable Energy, vol. 44, pp. 72-79, Aug. 2012.

[8]. K. Y. Lo, Y. M. Chen, and Y. R. Chang, "MPPT battery charger for standalonewind power system," IEEE Trans. Power Electron., vol. 26, no. 6,pp. 1631-1638, Jun. 2011.

[9]. E. Hau, Wind Turbines Fundamentals, Technologies, Application, Economics,2nd ed. New York, NY, USA: Springer, Dec. 2005.

\section{BIOGRAPHIES}

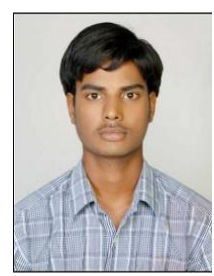

G.SANKAR BABU ${ }^{1}$ is presently pursuing M.Tech in Department of Electrical Engineering, Sri Venkateswara University College of Engineering, Tirupati, India. He received hisB.Tech degree from Jawaharlal Nehru Technological University, Anantapur in the year 2012. His areas of interest include electrical power systems, Electrical machines and renewable energy resources.

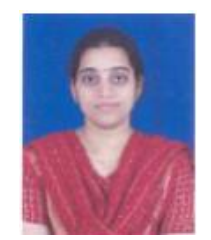

Smt. V. Usha Reddy ${ }^{2}$ has submitted her Ph.D in Jawaharlal Nehru Technological University College of Engineering, Hyderabad, India. She received her M.Tech from Sri Venkateswara University College of Engineering, Tirupati, India in 2007 and B.Tech from Jawaharlal Nehru Technological University, Hyderabad, India in 2003. Currently she is working as Assistant Professor in Department of Electrical Engineering, Sri Venkateswara University College of Engineering, Tirupati, India from last 7 years. She has 24 international journals, 5 international conferences publications. She has guided 10 M.Tech projects. Her specialization is Power Systems Operation and Control. 